\title{
A portable dermatoscope for easy, rapid examination of periungual nailfold capillary changes in patients with systemic sclerosis
}

\section{Eiji Muroi $^{1}$, Toshihide Hara ${ }^{1}$, Koichi Yanaba ${ }^{2}$, Fumihide Ogawa ${ }^{1}$, Ayumi Yoshizaki ${ }^{1}$, Motoi Takenaka $^{1}$, Kazuhiro Shimizu ${ }^{1}$, and Shinichi Sato ${ }^{3}$}

${ }^{1}$ Department of Dermatology, Nagasaki University Graduate School of Biomedical Sciences, Nagasaki, Japan; ${ }^{2}$ Department of Dermatology, The Jikei University School of Medicine, Tokyo, Japan; and ${ }^{3}$ Department of Dermatology, Faculty of Medicine, University

$$
\text { of Tokyo, Tokyo, Japan }
$$

Concise title: Dermatoscope in SSc

Keywords: systemic sclerosis, capillary abnormality, dermatoscope, enlarged capillary, hemorrhage

Conflicts of interest: None declared

Correspondening author: Shinichi Sato, MD, PhD, Department of Dermatology, Faculty of Medicine, Graduate School of Medicine, University of Tokyo, 7-3-1 Hongo, Bunkyo-ku, Tokyo 113-8655, Japan.

Phone: $+81-3-5800-8661$

Fax: +81-3-3814-1503

E-mail: satos-der@h.u-tokyo.ac.jp 


\begin{abstract}
Microvascular lesions are a predominant feature in systemic sclerosis (SSc) and seem to play a central pathogenic role. The presence of nailfold capillary abnormalities is useful in diagnosing SSc. Capillaroscopy, however, usually requires special equipment and may be time consuming. Dermatoscope has been presented as a new diagnostic tool for quick and efficient examination of nailfold capillaries for circumstances when standard microscope equipment is not available. To assess the practical utility of dermatoscope for assessment of capillary morphology in SSc patients, 83 Japanese SSc patients (68 women, 15men) and 68 healthy controls were examined in the study. Twenty-one patients (16 women, 5 men) had diffuse cutaneous SSc and 62 (52 women, 10 men) had limited cutaneous SSc. Enlarged capillaries and hemorrhages were evaluated in all 10 fingers with either naked eyes or DermLite $^{\circledR}$ DL100 dermatoscope. Enlarged capillaries and hemorrhages were significantly more frequently detected with dermatoscope than without it. These findings were observed most frequently in the fourth finger. The presence of two or more enlarged capillaries in one or more fingers showed $83.1 \%$ sensitivity and $100 \%$ specificity for SSc. Among SSc patients with anti-topoisomerase I antibody, the disease duration correlated negatively with the dermatoscopic number of enlarged capillaries and hemorrhages. Dermatoscope allows the easy and rapid identification of capillary nailfold morphological changes in SSc and should be routinely used for diagnosing SSc.
\end{abstract}




\section{Introduction}

Systemic sclerosis ( $\mathrm{SSc}$ ) is a connective tissue disease that affects various tissues and organs, including peripheral vessels, skin, lungs, kidneys, gastrointestinal tract, and cardiovascular system. The pathophysiology of SSc is complex and consists of three major features: vascular damage, followed by mononuclear cell infiltration, and massive deposition of newly synthesized connective tissue, mainly collagen $[1,2]$. The mechanism of vascular damage is not well understood. However, microvascular lesions are a predominant feature in SSc and seem to play a central pathogenic role.

In connective tissue diseases, local vascular changes can be studied by capillary microscopy of the nailfold, where abnormalities appear earlier in the course of the disease than at other sites of the finger skin $[3,4]$. Enlarged capillary and hemorrhage are important capillaroscopic changes. It has been suggested that enlarged capillaries represent a local autoregulatory response to tissue hypoxia [5]. The dilation may represent the first sign of vessel wall damage, and the increased red color is related to the greater number of red blood cells [6]. Local hemorrhages is also linked to the damage of the vessel wall [6]. The presence of capillary abnormalities may aid in early diagnosis of SSc, dermatomyositis, and mixed connective tissue disease and in the differential diagnosis of primary Raynaud's phenomenon from Raynaud's phenomenon due to SSc and mixed connective tissue disease $[3,7,8]$. The diagnostic sensitivity of the SSc classification criteria proposed by American College of Rheumatology may be markedly improved by addition of nailfold capillary microscopy abnormality [9]. However, capillary microscopy requires special equipment, including a biomicroscope or operating microscope [3], which often necessitates an additional appointment or a referral to a specialized center [10].

Dermoscopy is a noninvasive method that allows for magnified in vivo visualization of various anatomical elements within human skin. Dermatoscope has become an increasingly valuable tool to dermatologists for noninvasively assessing malignancy risk of pigmented skin 
lesions at the bedside [11]. The more recent availability of hand-held, battery-powered dermoscopy units employing a polarized light source to eliminate reflection from the skin surface, thereby eliminating the need for applying mineral oil/immersion to the skin surface, has made dermoscopy much more practical in a high volume outpatient setting such as a dermatology practice. Dermatoscope has been presented as a new diagnostic tool for quick and efficient examination of nailfold capillaries for circumstances when standard microscope equipment is not available [7, 12-15]. The capillaroscopic results obtained with the dermoscopy are comparable to those described with capillary microscopy $[14,15]$.

In this study, we examined enlarged capillary and hemorrhage in patients with SSc to evaluate the practical utility of portable dermatoscope for diagnosing SSc. Furthermore, we determined scleroderma pattern criteria with dermoscopy, and revealed relationship between dermatoscopic findings and clinical features. 


\section{Materials and Methods}

\section{Patients}

A total of 83 Japanese patients with SSc (68 women, 15men) were evaluated. All patients fulfilled the criteria proposed by the American College of Rheumatology [16]. Patients were grouped according to the classification system proposed by LeRoy et al. [17]: 21 patients (16 women, 5 men) had diffuse cutaneous SSc (dSSc) and 62 (52 women, 10 men) had limited cutaneous SSc (1SSc). The disease duration of patients with dSSc and 1SSc (mean $\pm \mathrm{SD})$ was $6.0 \pm 5.4$ and $11.4 \pm 10.4$ years, respectively. Antinuclear antibody $(\mathrm{Ab})$ was determined by indirect immunofluorescence and autoantibody specificities were further assessed by enzyme-linked immunosorbent assay and immunoprecipitation. Anti-topoisomerase I Ab was positive for 16 patients, anti-centromere $\mathrm{Ab}$ for 40 , anti-U1RNP $\mathrm{Ab}$ for one, anti-U3RNP Ab for two, anti-RNA polymerases I and III $\mathrm{Ab}$ for six, and $\mathrm{Th} / \mathrm{To}$ $\mathrm{Ab}$ for one. Six patients had antinuclear $\mathrm{Ab}$; however, their specificities were not identified. The remaining 11 patients were negative for autoantibody. Age- and sex-matched 68 Japanese healthy individuals were used as normal controls.

\section{Dermoscopy}

DermLite DL100 ${ }^{\circledR}$ (3Gen LLC, CA) is a very compact size dermatoscope $(99 \mathrm{~g})$ that provides fixed cross-polarization, allowing oil free (“dry”) epi luminescence. It employs a 1-mm x 10 Hastings triplet lens and diode lighting from eight light-emitting diodes. No oil or water on the finger is necessary. The nailfolds of all 10 fingers were examined in each patient. The following two parameters were considered and counted, according to previous classifications: enlarged capillaries and hemorrhages with either naked eyes or DermLite ${ }^{\circledR}$ DL100 (Fig. 1) [6]. The number more than six was recorded as six. Fingers affected by recent local trauma were not analyzed. During this study, the patients were variably treated with vasodilators, low dose aspirin, proton pump inhibitors, as well as immunosuppressive agents. 


\section{Statistical analysis}

Chi-square test was used to compare frequencies. The Mann-Whitney U-test was used to compare discontinuous data. Spearman's rank correlation coefficient was used to examine the relationship between two continuous variables. A p values less than 0.05 were considered statistically significant. 


\section{Results}

\section{Frequency of enlarged capillaries}

With naked eyes, enlarged capillaries were observed in 24 of 83 total patients with SSc (28.9\%), 5 of 21 patients with dSSc (23.8\%), and 19 of 62 patients with 1 SSc $(30.6 \%)$, but not in normal controls $(0 / 68,0 \%$; Table 1$)$. By contrast, when using dermatoscope, the prevalence of enlarged capillaries was significantly higher in total patients with SSc $(75 / 83,90.4 \%$, $\mathrm{p}<0.01)$, those with $\operatorname{dSSc}(18 / 21,85.7 \%, \mathrm{p}<0.01)$, and those with $1 \mathrm{SSc}(57 / 62,91.9 \%, \mathrm{p}<0.01)$. However, 9 of 68 controls (13.2\%) had enlarged capillaries with dermatoscope, which was significantly higher than with naked eyes $(p<0.01)$. Similarly, the total number of enlarged capillaries observed with dermatoscope was significantly 8.8-, 8.5-, and 9.0-fold higher than those with naked eyes in SSc $(p<0.01), \operatorname{dSSc}(p<0.01)$, and 1SSc $(p<0.01)$, respectively. The frequency and number of enlarged capillaries in patients with dSSc were not significantly different from those with 1SSc with both naked eyes and dermatoscope.

\section{Frequency of hemorrhages}

With naked eyes, hemorrhages were detected in 29 of 83 total patients with SSc (34.9\%), 10 of 21 patients with dSSc (47.6\%), and 19 of 62 patients with $1 \mathrm{SSc}(30.6 \%)$, but not in normal controls $(0 / 68,0 \%$; Table 1$)$. On the other hand, when using dermatoscope, $66.3 \%(55 / 83)$ of SSc patients, $62.9 \%(39 / 62)$ of 1 SSc patients, and $14.7 \%(10 / 68)$ of normal controls exhibited hemorrhages, which was significantly higher than the prevalence with naked eyes $(\mathrm{p}<0.01, \mathrm{p}<0.01$, and $\mathrm{p}<0.01$, respectively). However, 76.2\% (16/21) of dSSc patients exhibited hemorrhages, which tended to be higher than the prevalence with naked eyes $(p=0.06)$. Furthermore, the total number of hemorrhages observed with dermatoscope was significantly 3.9-, 3.8-, and 3.9-fold higher than those without it in SSc $(\mathrm{p}<0.01)$, dSSc $(p<0.01)$, and 1SSc $(p<0.01)$, respectively. The frequency and number of enlarged capillaries in patients with dSSc were not significantly different from those with 1SSc with both naked 
eyes and dermatoscope.

\section{Distribution and number of fingers showing enlarged capillaries}

Enlarged capillaries were observed most frequently in the right fourth finger in SSc (70.8\%), right and left fourth finger in dSSc (80.0\%), and right fourth finger in 1SSc (68.4\%) with naked eyes (Table 2). With dermatoscope, it was detected most frequently in the left fourth finger $(77.3 \%)$, left fifth finger $(94.4 \%)$, left fourth finger $(75.4 \%)$, and right fourth finger (33.3\%) in SSc, dSSc, 1SSc, and normal controls, respectively. In addition, the number of fingers with enlarged capillary in patients with SSc, dSSc, or 1SSc was significantly higher than in normal controls $(\mathrm{p}<0.01$, respectively). Furthermore, the number of fingers with enlarged capillaries in patients with dSSc was significantly higher than in $\operatorname{lSSc}(\mathrm{p}<0.05)$.

When the presence of two or more enlarged capillaries in one or more fingers was defined as "scleroderma pattern", it showed an $83.1 \%$ sensitivity and a $100 \%$ specificity for SSc.

\section{Distribution and number of fingers showing hemorrhages}

Hemorrhages were observed most frequently in the right fourth finger in SSc (55.2\%), dSSc $(50.0 \%)$, and $1 \mathrm{SSc}(57.9 \%)$ without dermatoscope (Table 3). With dermatoscope, it was detected most frequently in the left fourth finger (49.1\%), right third and fourth finger (56.3\%), right fifth finger (53.8\%), and right fifth finger $(40.0 \%)$ in SSc, dSSc, 1SSc, and normal controls, respectively. Furthermore, the number of fingers with hemorrhages in patients with $\mathrm{SSc}, \mathrm{dSSc}$, or $1 \mathrm{SSc}$ was significantly higher than in normal controls $(\mathrm{p}<0.01$, respectively). We could not recognize any significant difference in the number of fingers with hemorrhages between dSSc patients and 1SSc patients with both naked eyes and dermatoscope. 


\section{Clinical correlation of enlarged capillary and hemorrhage}

We investigated correlation of the dermatoscopic numbers of enlarged capillaries and hemorrhages with disease subsets, autoantibody specificities, and disease duration. Among patients with anti-topoisomerase $\mathrm{I} \mathrm{Ab}$, the duration of cutaneous sclerosis correlated negatively with the dermatoscopic numbers of enlarged capillaries and hemorrhages $(r=-0.537$, $\mathrm{p}<0.05$ and $\mathrm{r}=-0.728, \mathrm{p}<0.01$, respectively; Fig. 2). However, no other correlation was detected (data not shown). 


\section{Discussion}

Dermatoscope has been presented as a new diagnostic tool for quick and efficient examination of nailfold capillaries [7, 12-15]. A former study could demonstrate totally comparable results to those using more sophisticated instruments [13]. The $\kappa$ statistic between standard capillary microscope and dermatoscope was 0.93 for dilated capillaries and 0.94 for micro-hemorrhages [15]. Thus, for the clinical practice the capillary microscope can be replaced by a dermatoscope for the early detection of capillary changes. In this study, the presence or number of enlarged capillaries and hemorrhages was evaluated. The following capillaroscopic parameters have been known: the presence of enlarged and giant capillaries, hemorrhages, loss of capillaries, disorganization of the microvascular array, and capillary ramifications [18, 19]. The most frequent changes in SSc are enlarged capillaries [19], hemorrhages [20], and avascular areas [18, 21]. Enlarged capillary and giant capillary were defined as follows: enlarged capillary; an increase in capillary diameter (homogenous or irregular) $>20 \mu \mathrm{m}$ and giant capillary; homogenously enlarged loops with a diameter $>50 \mu \mathrm{m}$ ) [22]. Giant capillaries may represent one end of a continuous spectrum of capillary sizes. Furthermore, because of the impossibility of making actual measurement with dermatoscope, it is difficult to distinguish between those two terms. Therefore, we thought that it was appropriate to define enlarged and giant capillary as enlarged capillary in this study. On the other hand, there is poor reliability regarding avascular areas with dermatoscope [14]. For capillary ramifications, there were $\sim 10 \%$ false-negative examinations [15]. Thus, we selected enlarged capillaries and hemorrhages to establish a simple and rapid method.

Dermatoscope facilitated us to detect enlarged capillaries and hemorrhages. With dermatoscope, we detected enlarged capillaries nine times more frequently than without it, indicating that dermoscopy is useful in the observation of capillary abnormalities, enlarged capillary in particular. The frequency of hemorrhages is significantly higher in the fourth fingers than in the other fingers with naked eyes [23]. The most accurate morphological 
assessment with dermatoscope is commonly performed on the fourth and fifth fingers, because of the greater transparency of the skin on these fingers [6]. Consistent with this, the frequency of enlarged capillaries and hemorrhages was the highest in the fourth fingers from SSc patients. In addition, these changes were observed in more than one finger in patients with SSc. The results of this study showed that the presence of enlarged capillaries and hemorrhages in two or more fingers was specific for SSc. This indicates that the presence of enlarged capillaries and hemorrhages could be useful to screen SSc patients.

In the present study, we applied the definition of a "scleroderma pattern" that at least 2 enlarged capillaries have to be present in at least one nailfold. This criterion showed a sensitivity of $83.1 \%$ and a specificity of $100 \%$ in SSc. This "scleroderma pattern" was observed in $81.0 \%$ of dSSc cases and in $83.9 \%$ of $1 \mathrm{SSc}$ cases. In addition, when the first and second fingers were not evaluated, this criterion showed a sensitivity of $79.5 \%$ and a specificity of $100 \%$ in SSc. The "scleroderma pattern" was observed in $76.2 \%$ of dSSc cases and in $80.6 \%$ of $1 \mathrm{SSc}$ cases. A previous study using dermatoscope and the criterion that at least 2 of parameters (definitely or enormously dilated capillaries, avascular areas, hemorrhages, budding capillaries, and loss of the normal capillary beds) had to be present in at least 2 nailfolds, have shown a sensitivity of $70.4 \%$ and a specificity of $100 \%$ in 27 patients with SSc [13]. The other study using dermatoscope and the criterion that at least 2 of parameters (enlarged capillaries, avascular areas, hemorrhages, tortuous, crossed and arborized capillaries) are present have revealed a sensitivity of $76.9 \%$ and a specificity of $90.9 \%$ in 26 patients with SSc [7]. The sensitivity and specificity of our criteria were equivalent to those obtained by these previous studies. In addition, our criterion is more simple and quick, since it involves examination of only two parameters. Furthermore, in the clinical practice at least the third to fifth fingers should be evaluated, it is not necessary to evaluate the first and second finger.

It is well known that the capillary findings in SSc patients change with time. In our 
study, the lower number of enlarged capillaries and hemorrhages was associated with longer disease duration in SSc patients with anti-topoisomerase I Ab. The loss of capillaries represents the clearest aspect of advanced SSc microvascular damage [21]. The presence of anti-topoisomerase I Ab seems to be related to earlier expression of the late pattern: few or absent giant capillaries and hemorrhages, and severe avascular areas [18]. Furthermore, the severity of nailfold capillary microscopy abnormalities is associated with lung disease activity in SSc, particularly when the disease duration is relatively short [24]. These results suggest that the progression of microangiopathy is faster in SSc patients with anti-topoisomerase I Ab, which could explain why the number of enlarged capillaries and hemorrhages decreases during the disease course. Longitudinal studies will be required to reveal the correlation between dermatoscopic finding and disease activity or duration.

In conclusion, the results of our study indicate that dermatoscope is an easy, rapid, and suitable tool for screening SSc, especially early SSc, since microvascular changes are one of the earliest manifestations during the disease course [9]. Furthermore, the number of those findings might be useful both to assess and to follow up microvascular involvement in SSc. This study shows that the hand-held device should be used in clinical routine for efficient SSc diagnosis.

\section{Acknowledgment}

This work was supported by a grant of Research on Intractable Diseases from the Ministry of Health, Labour and Welfare of Japan. 


\section{References}

1. Sapadin AN, Esser AC, Fleischmajer R (2001) Immunopathogenesis of scleroderma--evolving concepts. Mt Sinai J Med 68:233-42.

2. Denton CP, Abraham DJ (2001) Transforming growth factor-beta and connective tissue growth factor: key cytokines in scleroderma pathogenesis. Curr Opin Rheumatol $13: 505-11$

3. Maricq HR (1981) Wide-field capillary microscopy. Arthritis Rheum 24:1159-65.

4. Houtman PM, Kallenberg CG, Fidler V, Wouda AA (1986) Diagnostic significance of nailfold capillary patterns in patients with Raynaud's phenomenon. An analysis of patterns discriminating patients with and without connective tissue disease. J Rheumatol 13:556-63.

5. Colwell JA, Halushka PV, Sarji KE, Lopes-Virella MF, Sagel J (1979) Vascular disease in diabetes: pathophysiological mechanisms and therapy. Arch Intern Med 139:225-30.

6. Cutolo M, Pizzorni C, Secchi ME, Sulli A (2008) Capillaroscopy. Best Pract Res Clin Rheumatol 22:1093-108.

7. Beltran E, Toll A, Pros A, Carbonell J, Pujol RM (2007) Assessment of nailfold capillaroscopy by x 30 digital epiluminescence (dermoscopy) in patients with Raynaud phenomenon. Br J Dermatol 156:892-8.

8. Blockmans D, Vermylen J, Bobbaers H (1993) Nailfold capillaroscopy in connective tissue disorders and in Raynaud's phenomenon. Acta Clin Belg 48:30-41.

9. Lonzetti LS, Joyal F, Raynauld JP, Roussin A, Goulet JR, Rich E, Choquette D, Raymond Y, Senecal JL (2001) Updating the American College of Rheumatology preliminary classification criteria for systemic sclerosis: addition of severe nailfold capillaroscopy abnormalities markedly increases the sensitivity for limited scleroderma. Arthritis Rheum 44:735-6.

10. Anders HJ, Sigl T, Schattenkirchner M (2001) Differentiation between primary and secondary Raynaud's phenomenon: a prospective study comparing nailfold capillaroscopy 
using an ophthalmoscope or stereomicroscope. Ann Rheum Dis 60:407-9.

11. Argenziano G, Soyer HP, Chimenti S, Argenziano G, Ruocco V (2002) Impact of dermoscopy on the clinical management of pigmented skin lesions. Clin Dermatol 20:200-2. 12. Sontheimer RD (2004) A portable digital microphotography unit for rapid documentation of periungual nailfold capillary changes in autoimmune connective tissue diseases. J Rheumatol 31:539-44.

13. Bergman R, Sharony L, Schapira D, Nahir MA, Balbir-Gurman A (2003) The handheld dermatoscope as a nail-fold capillaroscopic instrument. Arch Dermatol 139:1027-30.

14. Baron M, Bell M, Bookman A, Buchignani M, Dunne J, Hudson M, Jerome D, Johnson SR, Jones N, Kaminska E, Lupton T, Mathieu JP, Pope J, Steele R, Taillefer S (2007) Office capillaroscopy in systemic sclerosis. Clin Rheumatol 26:1268-74.

15. Bauersachs RM, Lossner F (1997) The poor man's capillary microscope. A novel technique for the assessment of capillary morphology. Ann Rheum Dis 56:435-7.

16. (1980) Preliminary criteria for the classification of systemic sclerosis (scleroderma). Subcommittee for scleroderma criteria of the American Rheumatism Association Diagnostic and Therapeutic Criteria Committee. Arthritis Rheum 23:581-90.

17. LeRoy EC, Black C, Fleischmajer R, Jablonska S, Krieg T, Medsger TA Jr, Rowell N, Wollheim F (1988) Scleroderma (systemic sclerosis): classification, subsets and pathogenesis. J Rheumatol 15:202-5.

18. Cutolo M, Pizzorni C, Tuccio M, Burroni A, Craviotto C, Basso M, Seriolo B, Sulli A (2004) Nailfold videocapillaroscopic patterns and serum autoantibodies in systemic sclerosis. Rheumatology (Oxford) 43:719-26.

19. Grassi W, Medico PD, Izzo F, Cervini C (2001) Microvascular involvement in systemic sclerosis: capillaroscopic findings. Semin Arthritis Rheum 30:397-402.

20. Sulli A, Burroni A, Tuccio M, Pizzorni C, Craviotto C, Ghio M, Basso M, Seriolo B, Cutolo M (2004) [Nailfold videocapillaroscopy in systemic sclerosis: diagnostic and 
follow-up parameters and correlation with both specific serum autoantibodies and subsets of skin involvement]. Reumatismo 56:36-45.

21. Cutolo M, Sulli A, Pizzorni C, Accardo S (2000) Nailfold videocapillaroscopy assessment of microvascular damage in systemic sclerosis. J Rheumatol 27:155-60.

22. Sulli A, Secchi ME, Pizzorni C, Cutolo M (2008) Scoring the nailfold microvascular changes during the capillaroscopic analysis in systemic sclerosis patients. Ann Rheum Dis 67:885-7.

23. Sato S, Takehara K, Soma Y, Tsuchida T, Ishibashi Y (1993) Diagnostic significance of nailfold bleeding in scleroderma spectrum disorders. J Am Acad Dermatol 28:198-203.

24. Bredemeier M, Xavier RM, Capobianco KG, Restelli VG, Rohde LE, Pinotti AF, Pitrez EH, Vieira MV, Fontoura MA, Ludwig DH, Brenol JC (2004) Nailfold capillary microscopy can suggest pulmonary disease activity in systemic sclerosis. J Rheumatol 31:286-94. 


\section{Figure Legends}

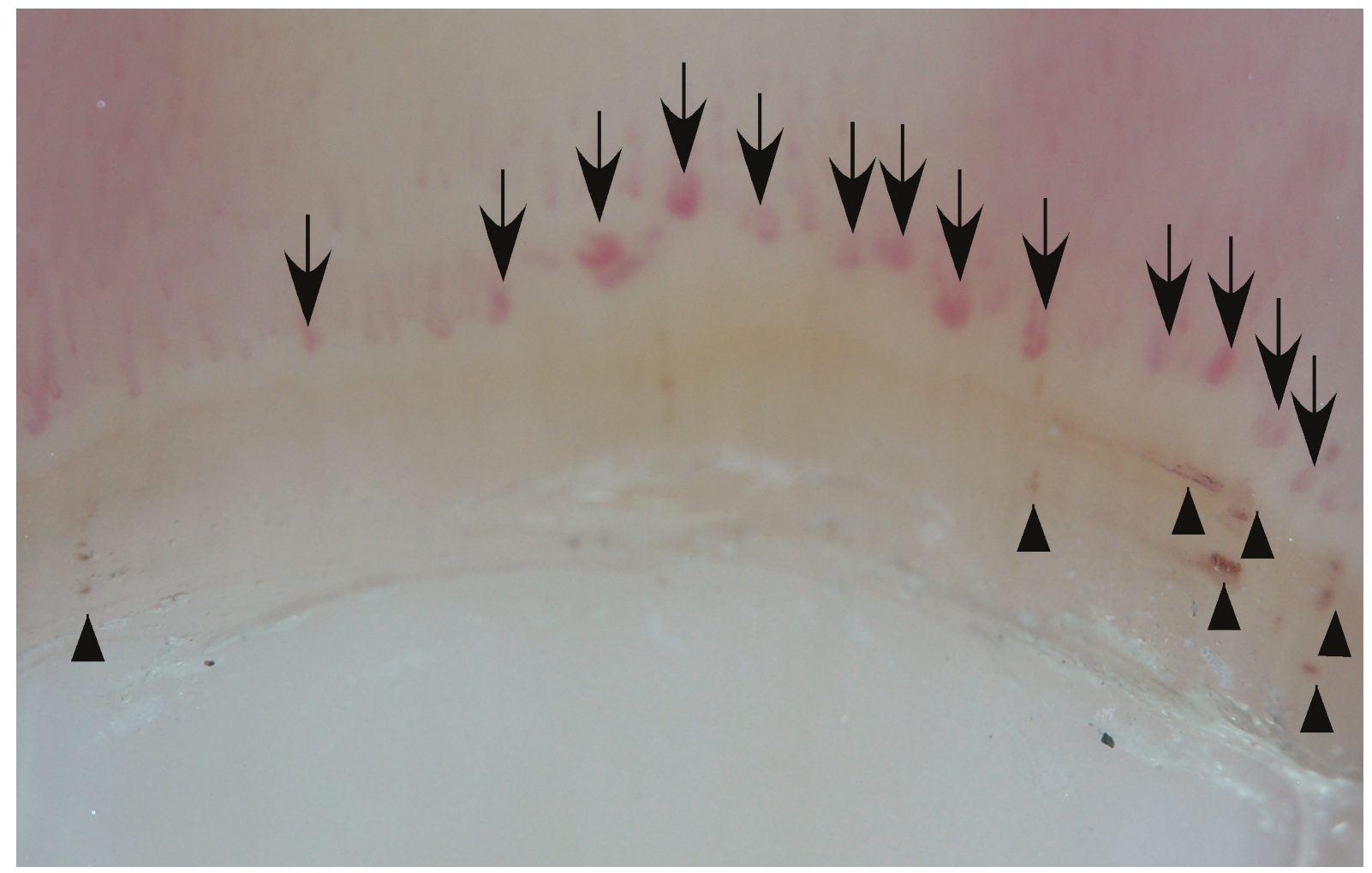

Fig. 1 Dermatoscopic image with enlarged capillaries and hemorrhages in a patient with SSc.

Arrows and arrowheads indicate enlarged capillaries and hemorrhages, respectively. 
(a)

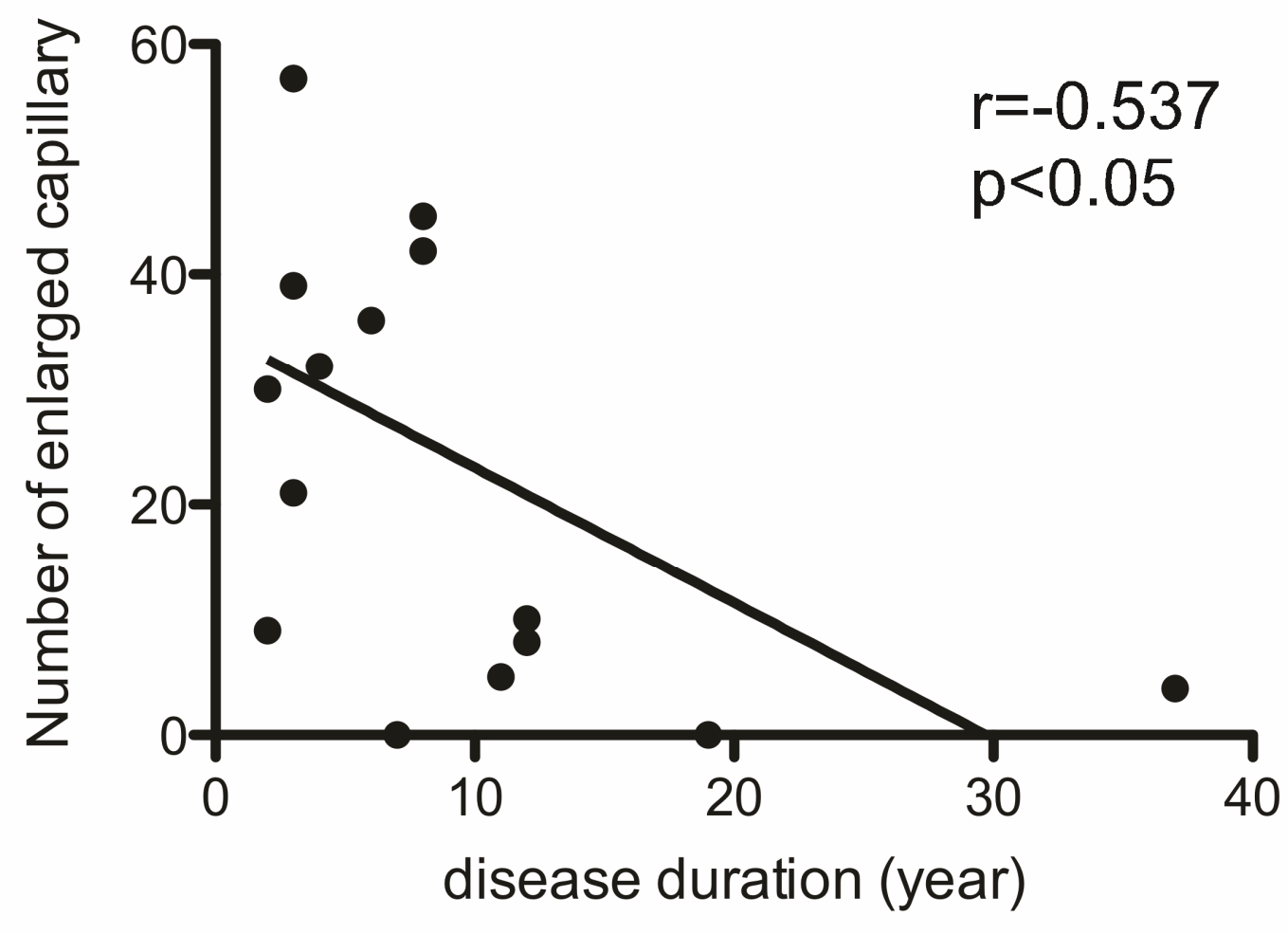

(b)

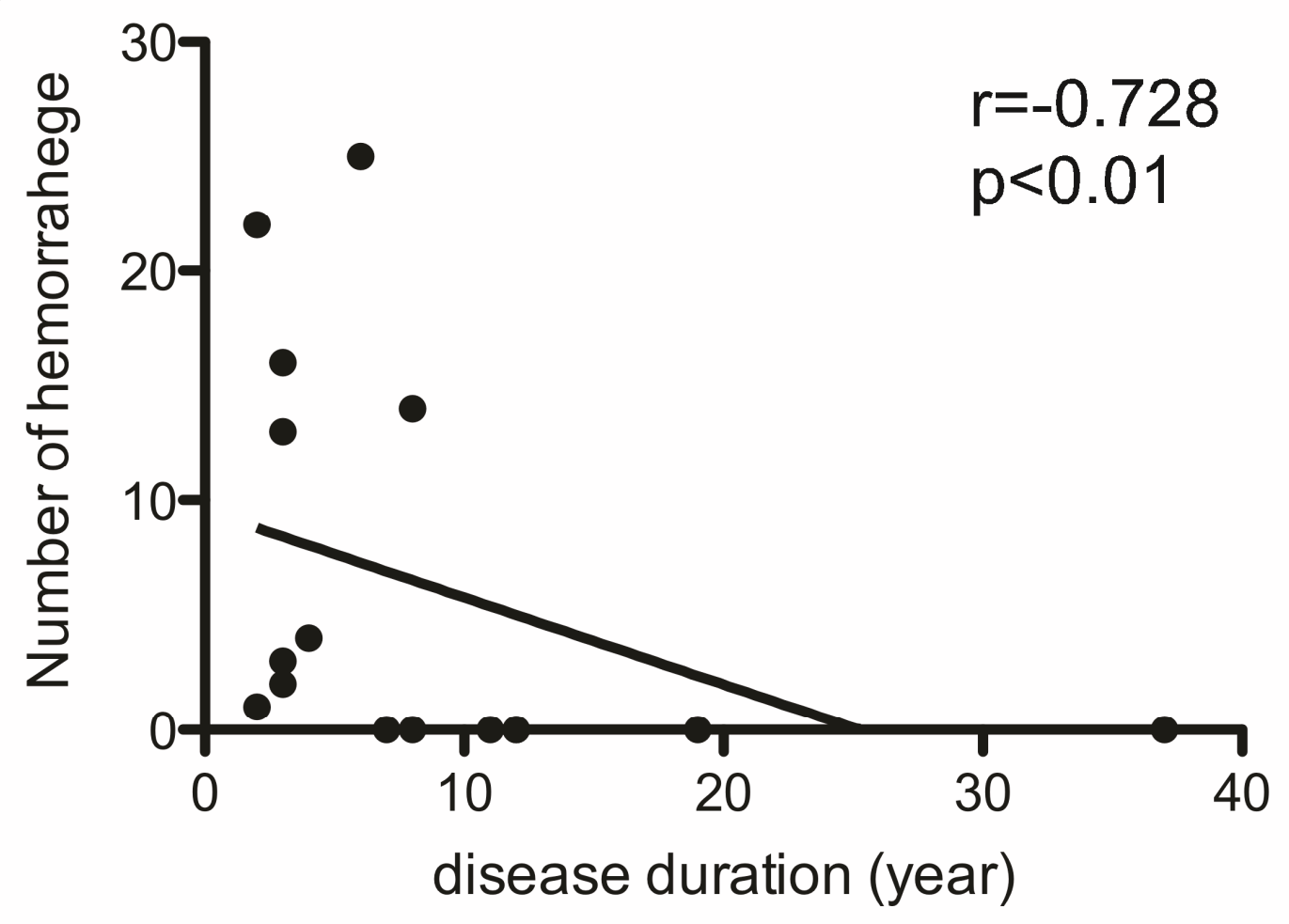

Fig. 2 Correlation of enlarged capillary (a) and hemorrhage (b) with disease duration in SSc patients with anti-topoisomerase I Ab. 
Table 1. Frequency of enlarged capillary and hemorrhage

\begin{tabular}{|c|c|c|c|c|c|c|c|c|}
\hline \multirow{3}{*}{$\begin{array}{l}\text { Diagnosis } \\
\text { (No. of patients) }\end{array}$} & \multicolumn{4}{|c|}{ Enlarged capillary } & \multicolumn{4}{|c|}{ Hemorrhage } \\
\hline & \multicolumn{2}{|c|}{ No. of patients (\%) } & \multicolumn{2}{|c|}{$\begin{array}{l}\text { No. of } \\
\text { enlarged capillary }(\text { mean } \pm \mathrm{SD})\end{array}$} & \multicolumn{2}{|c|}{ No. of patients (\%) } & \multicolumn{2}{|c|}{$\begin{array}{l}\text { No. of } \\
\text { hemorrhage }(\text { mean } \pm \mathrm{SD})\end{array}$} \\
\hline & $(-)$ & DS & $(-)$ & DS & $(-)$ & DS & $(-)$ & DS \\
\hline SSc (83) & $24(28.9)$ & $75(90.4))^{* *}$ & $200 \pm 5.2$ & $1762 \pm 17.6^{* *}$ & $29(34.9)$ & $255(66.3)^{* *}$ & $13138 \pm 3.3$ & $\overline{2536 \pm 8.3^{* *}}$ \\
\hline $\operatorname{dSSc}(21)$ & $5(23.8)$ & $18(85.7)^{* *}$ & $64 \pm 6.4$ & $542 \pm 18.8 * *$ & $10(47.6)$ & $16(76.2)$ & $44 \pm 3.7$ & $167 \pm 8.7^{* *}$ \\
\hline $1 \mathrm{SSc}(62)$ & $19(30.6)$ & $57(91.9)^{* *}$ & $136 \pm 4.8$ & $1220 \pm 17.0 * *$ & $19(30.6)$ & $39(62.9) * *$ & $94 \pm 3.1$ & $369 \pm 8.2 * *$ \\
\hline Control (68) & $0(0)$ & $9(13.2) * *$ & 0 & $10 \pm 0.4 *$ & $0(0)$ & $10(14.7)^{* *}$ & 0 & $18 \pm 0.7 * *$ \\
\hline
\end{tabular}

${ }^{*} \mathrm{p}<0.05 ; * * \mathrm{p}<0.01$ vs. the values without dermatoscope. 
Table 2. Distribution and number of fingers showing enlarged capillary

\begin{tabular}{|c|c|c|c|c|c|c|c|c|c|c|c|c|}
\hline & \multirow{2}{*}{$\begin{array}{l}\text { Diagnosis } \\
\text { (No. of patients) }\end{array}$} & \multicolumn{5}{|c|}{ Right fingers (\%) } & \multicolumn{5}{|c|}{ Left fingers $(\%)$} & \multirow{2}{*}{$\begin{array}{l}\text { No. of fingers } \\
(\text { mean } \pm \mathrm{SD})\end{array}$} \\
\hline & & 5 & 4 & 3 & 2 & 1 & 1 & 2 & 3 & 4 & 5 & \\
\hline \multirow[t]{4}{*}{$(-)$} & SSc (24) & 50.0 & 70.8 & 25.0 & 20.8 & 8.3 & 4.2 & 16.7 & $\begin{array}{l}41.7 \\
\end{array}$ & "50.0 & 16.7 & $3.0 \pm 1.9$ \\
\hline & dSSc (5) & 40.0 & 80.0 & 25.0 & 20.0 & 20.0 & 0.0 & 40.0 & 60.0 & 80.0 & 20.0 & $3.8 \pm 1.9$ \\
\hline & 1SSc (19) & 52.6 & 68.4 & 26.3 & 21.1 & 5.3 & 5.3 & 10.5 & 36.8 & 42.1 & 15.8 & $2.8 \pm 1.9$ \\
\hline & Control (0) & & & & & & & & & & & \\
\hline \multirow[t]{4}{*}{ DS } & SSc (75) & 58.7 & 64.0 & 58.7 & 37.3 & 26.7 & 29.3 & 42.7 & 65.3 & 77.3 & 68.0 & $5.30 \pm 2.9 * *$ \\
\hline & dSSc (18) & 66.7 & 66.7 & 77.8 & 44.4 & 55.6 & 33.3 & 55.6 & 77.8 & 83.3 & 94.4 & $6.60 \pm 2.9 * * \dagger$ \\
\hline & $1 \mathrm{SSc}(57)$ & 56.1 & 63.2 & 52.6 & 35.1 & 17.5 & 28.1 & 38.6 & 61.4 & 75.4 & 59.6 & $4.90 \pm 2.8 * *$ \\
\hline & Control (9) & 22.2 & 33.3 & 11.1 & 11.1 & 0.0 & 11.1 & 11.1 & 0.0 & 0.0 & 11.1 & $1.10 \pm 0.3$ \\
\hline
\end{tabular}

(-): without dermatoscope, DS: with dermatoscope.

$* * \mathrm{p}<0.01$ vs. control.

$\dagger \mathrm{p}<0.05$ vs. $1 \mathrm{SSc}$ 
Table 3. Distribution and number of fingers showing hemorrhage

\begin{tabular}{|c|c|c|c|c|c|c|c|c|c|c|c|c|}
\hline & \multirow{2}{*}{$\begin{array}{l}\text { Diagnosis } \\
\text { (No. of patients) }\end{array}$} & \multicolumn{5}{|c|}{ Right fingers (\%) } & \multicolumn{5}{|c|}{ Left fingers (\%) } & \multirow{2}{*}{$\begin{array}{l}\text { No. of fingers } \\
(\text { mean } \pm \mathrm{SD})\end{array}$} \\
\hline & & 5 & 4 & 3 & 2 & 1 & 1 & 2 & 3 & 4 & 5 & \\
\hline \multirow[t]{4}{*}{$(-)$} & SSc (29) & 34.5 & 55.2 & 13.8 & 24.1 & 10.3 & 0.0 & 0.0 & 31.0 & 31.0 & 31.0 & $2.3 \pm 1.5$ \\
\hline & $\mathrm{dSSc}(10)$ & 20.0 & 50.0 & 20.0 & 40.0 & 20.0 & 10.0 & 0.0 & 30.0 & 20.0 & 20.0 & $2.3 \pm 2.1$ \\
\hline & $1 \mathrm{SSc}(19)$ & 42.1 & 57.9 & 10.5 & 15.8 & 5.3 & 0.0 & 0.0 & 31.6 & 36.8 & 36.8 & $2.4 \pm 1.1$ \\
\hline & Control (0) & & & & & & & & & & & \\
\hline \multirow[t]{4}{*}{ DS } & SSc (55) & 43.6 & 43.6 & 41.8 & 30.9 & 16.4 & 20.0 & 18.2 & 41.8 & 49.1 & 47.3 & $3.5 \pm 2.1 * *$ \\
\hline & dSSc (16) & 18.8 & 56.3 & 56.3 & 31.3 & 25.0 & 18.8 & 18.8 & 37.5 & 50.0 & 43.8 & $3.6 \pm 2.1 * *$ \\
\hline & $1 \mathrm{SSc}(39)$ & 53.8 & 38.5 & 35.9 & 30.8 & 12.8 & 20.5 & 17.9 & 43.6 & 48.7 & 48.7 & $3.5 \pm 2.1 * *$ \\
\hline & Control (10) & 40.0 & 10.0 & 0.0 & 10.0 & 10.0 & 10.0 & 20.0 & 0.0 & 10.0 & 10.0 & $1.2 \pm 0.6$ \\
\hline
\end{tabular}

(-): without dermatoscope, DS: with dermatoscope.

$* * \mathrm{p}<0.01$ vs. control. 